\title{
Gerenciamento do setor saúde na década de 80 , no Estado de São Paulo, Brasil
}

\author{
Health management in the State of S. Paulo, Brazil
}

Oswaldo Yoshimi Tanaka*, Eulália Maria A. Escobar**, Aparecida Silvia M. Gimenez Katia G. Camargo Carmen L.S. Lell, Tania M. Yoshida

\begin{abstract}
TANAKA, O.Y. et al. Gerenciamento do setor saúde na déçada de 80, no Estado de São Paulo, Brasil. Rev. Saúde públ., S. Paulo, 26: 185-94, 1992. Foi analisado o processo de gerenciamento colegiado implementado pelas Ações Integradas de Saúde (AIS), no Estado de São Paulo, na década de 80. A base de dados foi constituída por informaçōes coletadas junto à Comissão Interinstitucional de Saúde (CIS-SP). Foram também investigadas a participação dos diversos representantes, as decisões e as resoluções originadas nessa instância de gerenciamento do sistema de saúde. A análise conjunta das informações coletadas mostrou que houve mudança substancial no papel de gerenciamento do setor saúde no Estado, principalmente a partir de 1987. O processo de gestão colegiada, iniciada com as AIS, foi sendo substituído paulatinamente pela gestão única, com a separação nítida das responsabilidades entre os niveis de governo municipal, estadual e federal. Esta mudança dificultou o processo de negociação e de definição de objetivos comuns entre os responsáveis pela política de saúde, que vinham sendo constituídos no Estado desde as AIS.
\end{abstract}

Descritores: Administração pública, tendências. Relações interisnstitucionais. Administração sanitária, tendências. Sistema de saúde, organização e administração

\section{Introduçäo}

As diretrizes políticas implementadas pelo setor saúde, na década de 80 , impulsionaram modificaçōes substanciais nas instituiçōes responsáveis pela prestação de serviços de saúde.

Uma nova forma de acesso e de prestação do serviços foi se estabelecendo entre os diferentés prestadores, em decorrência da definição de novas competências e de responsabilidades, entre as diversas instâncias do poder executivo.

As diretrizes de descentralizaçāo e de intregraçāo funcional, impulsionadas por essas políticas, ocasionaram modificações nas estruturas organizacionais e nos procedimentos administrativos utilizados pelas diversas instituiçōes, principalmente públicas, envolvidas no processo.

- Departamento de Saúde Matemo-Infantil da Faculdade de Sride Pública da Universidade de São Paulo - S5́o Paulo, SP - Brasil.

* Departamento de Enfermagem da Escola Paulista de Mo dicina - Sa o Paulo, SP - Bmsil.

*** Frouldade de Enfermagem da Pontificia Universidade Católica de Campinas - Campinas, SP - Brasil.

*** Curso de Nutricia da Faculdade de Saride Priblica da Universidade de Sảo Paulo - Săo Paulo, SP - Brasil

*****Curso de Ciencia Sociais da Faculdade de Filosofia, Lo tras e Ciéncias Humanas da Universidade de Så Paulo São Paulo, SP - Brasil.

Sepantas/Reprints: O.Y. Tanalca - Av. Dr. Amaldo, 715 01246-904 - São Paulo, SP - Brasil.

Publicação financiada pela FAPESP. Processo Saúde Coletiva 91/4994-0.
Dentre essas modificaçōes torna-se importante analisar a funçäo do gerenciamento das instituiçōes públicas responsáveis pela prestação de serviços de saúde à comunidade.

Este trabalho propôe-se a analisar o processo de gestāo colegiada ocorrida, no setor público, a partir da década de 80. Para tanto, faz-se necessária a recuperação, de uma forma analítica e crítica, da trajetória do setor saúde, nas últimas décadas.

Durante a década de 70 , houve um processo de integração e fortalecimento da assistência médico-hospitalar de característica curativa, na área da Previdência. Em 1975, com a Lei 6.229/75, era criado o Sistema Nacional de Saúde (SNS) que se determinava a: "organizar o complexo de serviços do setor público e privado, voltados para as ações de interesse da saúde", partindo do diagnóstico da dispersão de recursos e indefinição de competências das entidades públicas e privadas do setor, como as principais causas de seu desempenho inadequado ${ }^{17}$.

O SNS procurava coordenar as ações da medicina previdenciária, que neste momento já vinham adquirindo autonomia em relação à política nacional de saúde formulada pelo Ministério da Saúde (MS).

A V Conferência Nacional de Saúde (CNS) foi realizada alguns meses após a promulgação da Lei $6.229 / 75$, tendo como tema principal o 
SNS, enfatizando a visão sistêmatica concebida para o setor, reforçado o enfoque racionalizador da proposta 2 .

A partir de então, a integração dos serviços voltados às açōes de saúde pública começou a ser enfatizada. No entanto, a autonomia atingida pela medicina previdenciária mantinha 0 atendimento médico individual curativo em taxas ascendentes.

Neste contexto ocorreu, em 1976, a reestruturação do MS, com a criação da Secretaria de Ações Básicas de Saúde (SNPES), responsável pelos programas de assistência médico-sanitária. O MS passava a ter, com esta estrutura, maior racionalidade administrativa e melhor coordenação com as Secretarias Estaduais de Saúde, as quais eram responsáveis diretas pela execução açōes. A atuação da SNPES caracterizou-se pelo reforço à programação médico-sanitária implantada na rede básica a partir da $\mathrm{V}$ Conferência Nacional de Saúde. A definição de programas especificos fragmentou novamente a prestação de serviços de saúde, os quais passaram a ser verticalizados, tanto do ponto de vista técnico como do ponto de vista do gerenciamento dos unsumos básicos necessários à realização dos programas.

No processo de revitalização pelo qual a saúde pública vinha passando, destacava-se o Programa de Interiorização das Açōes de Saúde e Sanearnento (PIASS) aprovado em 1976, destinado a implantar e implementar uma estrutura de rede básica de serviços de assistência médico-sanitária em locais de baixa densidade demográfica, sobretudo na região nordeste do país.

O PIASS tinha como diretrizes básicas a utilização ampla de pessoal de nivel auxiliar, com ênfase nas atividades preventivas e previa a integração em nível local dos diferentes serviços de saúde sob a responsabilidade das Secretarias Estaduais de Saúde. Esta diretriz constituia-se no prenúncio da gestão colegiada preconizada na década seguinte ${ }^{16}$. O PIASS constituise no tema central da VI CNS realizada em $1977^{3}$.

Em 1977 foi criado o Sistema Nacioanal de Previdência Social (SIMPAS) pela Lei 6.439/77, e neste, o Instituto Nacional de Assistência Médica da Previdência Social (INAMPS) responsável pela prestação de assistência médica individual previdenciária existentes na época ${ }^{17}$.

De forma semelhante ao ocorrido no Ministério da Saúde, a criação do INAMPS acartetou um processo de centralização técnico-administrativa das decisões no âmbito da assistência médica individual de caráter curativo.
Nesse período foi mantida a autonomia da política previdenciária e o seu papel social compensador, não tendo sido alterado o modo de produção da assistência médico-hospitalar predominantemente voltado para a manutenção da saúde individual dos trabalhadores.

Em março de 1980, uma Portaria Interministerial cria a Comissão Interministerial de Planejamento (CIPLAN), ficando com a responsabilidade do planejamento geral e da programação das atividades de natureza médico-assistencial e sanitária que eram do âmbito do Ministério da Saúde (MS) e do Ministério da Previdência e Assistência Social (MPAS) ${ }^{18}$.

A CIPLAN caracterizou-se como uma primeira proposta formal de planejamento conjunto à área da saúde pública e com a medicina previdenciária.

Concomitantemente à criação de CIPLAN, foi realizada a VII $\mathrm{CNS}^{4}$ cujo tema basico era a extensão das ações de saúde através dos serviços básicos, reforçando as propostas políticas da Conferência Internacional sobre Cuidados Primários de Saúde, Alma-Ata, em 1978!.

Na VII CNS, ocorrida já sob a égide do MS e do MPAS, foram lançadas as bases para o Programa Nacional de Serviços Básicos de Saúde (PREV-SAÚDE).

O PREV-SAÚDE apresentava como característica principal uma estratégia de integração de maior abrangência, envolvendo o MS, o MPAS, o Ministério do Interior (MI) e a Secretaria de Planejamento da Presidência da República (SEPLAN), possuindo objetivos bastante ambiciosos, como o de estender a cobertura dos serviços básicos de saúde a toda população, de reorganizar o setor público de saúde articulando as várias instituições, e de reordenar a oferta dos serviços, além de promover a melhoria das condições gerais do ambiente ${ }^{10}$. A oposição criada pelas entidades privadas e instituições públicas ligadas ao INAMPS e pelos próprios técnicos dos Ministérios, levaram a modificações substanciais ao projeto original, restringindo tanto o programa, que este acabou constituindo-se apenas em uma proposta de reordenação do setor público prestador de serviços de saúde.

Simultaneamente ao PRE-SAÚDE, a crise do custeio da assistência médico-hospitalar ia agravando-se, corroborada pela política econômica recessiva do Governo Federal, adotada a partir de 1980. Esta crise fazia com que houvesse necessidade de medidas administrativas para que se recompusesse o equilibrio do sistema ${ }^{17}$.

Nesse sentido, em 1981, foi criada o Conselho Consultivo de Administração de Saúde 
Previdenciária (CONASP) com o objetivo de estudar e propor normas mais adequadas à prestação de assistência à saúde da população previdenciária, assim como indicar a necessária alocação de recursos financeiros ou de qualquer outra natureza, indispensáveis à operação da rede de serviços.

Com tais diretrizes foi apresentado e aprovado, em 1982, o Plano de Reorientação da Assistência à Saúde no âmbito da Previdência Social (Plano do CONASP), que tinha entre os seus objetivos principais a melhoria da qualidade da assistência à saúde, a cobertura desses serviços da forma igualitária para a população rural e urbana, o planejamento da assistência à saúde de acordo com parâmetros definidos $\mathrm{e} o$ aumento da produtividade com a racionalização de serviços. Dentre as 17 propostas de intervenção do Plano CONASP destacava-se o Programa das Ações Integradas de Saúde (PAIS) que preconizava a regionalizaçao progressiva do sistema de saúde, planejado e coordenado por comissāo paritária.

O Programa das Ações Integradas de Saúde logo foi transformado em estratégia AIS. Esta, propunha modificaçōes substanciais no setor, por meio da otimização dos serviços públicos de saúde, a fim de atender a uma demanda crescente por assistência médica.

As AIS tinham como objetivo integrar e racionalizar o atendimento médico tornando os serviços de diferentes níveis de complexidade mais acessíveis à população.

As AIS propunham como instâncias de planejamento e gestāo: a Comissão Interministerial de Planejamento (CIPLAN), as Comissões Interinstitucionais de Saúde (CIS), as Comissões Regionais Interinstituicionais de Saúde (CRIS) e as Comissões Locais e/ou Municipais de Saúde (CLIS ou CIMS).

A CIPLAN, já citada anteriormente, constituia-se no órgão deliberativo interministerial que deveria fornecer pautas de atuaçāo integrada e efetiva das instituições federais e realizar 0 acompanhamento das AIS, ao nivel nacional ${ }^{5}$.

As CIS deveriam constituir-se em instâncias decisórias e gestoras das AIS em nivel de cada unidade federada, e as CRIS, CLIS, CIMS em nivel das regionais de saúde e dos municípios.

A CIPLAN deveria integrar as ações de planejamento do MPAS, do MS e do Ministério da Educaçāo e Cultura (MEC) e ao presidente do Conselho Nacional dos Secretários de Saúde (CONASS) ${ }^{5}$.

As CIS deveriam ser compostas, inicialmente, pelo Secretário Estadual de Saúde, pelo
Superintendente Regional do INAMPS e por representantes do MS e do MEC ${ }^{5}$.

As CRIS deveriam integrar-se os participantes das instituições convenentes, acrescidos dos representantes das secretarias municipais de saúde, bem como das entidades comunitátias, sindicais, gremiais, representando a população em geral.

Estes órgãos de gestão colegiada nos diferentes niveis do governo deveriam garantir a necessária coordenação entre os diversos serviços e teriam a competência de redefinir as políticas de saúde no seu âmbito de ação.

Dessa maneira, a organização funcional proposta pelas AIS, nas distintas instâncias de poder, se constituem num intento real de viabilizar a gestão colegiada envolvendo os órgãos públicos prestadores de serviços de saúde.

No Estado de São Paulo, as AIS tiveram início em Outubro de 1983, com a assinatura do Convênio $7 / 83$ que se iniciava com a adesão do Município de São Paulo ${ }^{13}$.

E portanto, a partir de meados da década de 80 , que os órgãos de gestão colegiada aparecem na condução dos serviços de saúde no Estado de São Paulo.

A reforma administrativa da Secretaria de Estado da Saúde de São Paulo (SES-SP), ocorrida em 1985, veio reforçar o processo de gerenciamento colegiado no Estado, tendo sido primordial para o avanço do processo a criação dos Escritórios Regionais de Saúde (ERSA), que se constituiam nas instâncias descentralizadas de decisão da SES-SP.

Com o advento do Programa Sistema Unificado e Descentralizado de Saúde (SUDS), em 21 de maio de 1987, os convênios AIS foram, paulatinamente, sendo substituídos pelos convênios SUDS, cujas bases institucionais eram a municipalização da rede básica de saúde, a definição de uma política hospitalar e a implementação de uma estrutura programática comum dentro do Estado 6,7.

O termo de compromisso do SUDS propunha a utilização plena da CIS-SP, "como o órgão decisório final das propostas do compromisso interinstitucional", recomendando a mudança da sua estrutura, a qual deveria passar a incorporar a representação dos municípios e dos usuários"

Em síntese, o gerenciamento dos serviços de saúde, na década de 70, caracterizaram-se por um gerenciamento centralizado, uni-institucional, com acentuado caráter normativo e com nítida separação entre as ações preventivas e curativas. Enquanto que, a década de 80 , devido principalmente às pressões sociais e à presença 
de novos executivos municipais, que respaldados por eleições democráticas, reivindicam maior autonomia, observa-se a implementação da gestão colegiada das instituiçōes prestadoras de serviços de saúde nos diferentes níveis de poder. Cabe realçar que a relação com o setor privado foi mantido basicamente sob a responsabilidade do INAMPS até o advento do SUDS.

Portanto, nesse início da década de 90 , em que o processo de democratização do pais encontra-se em franca evolução, com possibilidades crescentes de manifestação das distintas camadas da sociedade, faz-se necessário a busca de uma adequada compreensão dos diferentes tipos de gerenciamento havidos nas instituições públicas na década de 80 , os quais poderão servir de base para a construção consciente de um novo modelo assistencial capaz de responder, efetivamente, às reais necessidades de saúde da população.

\section{Metodologia}

A coleta de dados para o presente estudo iniciou-se em janeiro de 1990 tendo sido concluida em julho do mesmo ano.

A Secretaria de Estado da Saúde de São Paulo (SES-SP), por constituir-se durante a década, no órgão responsável pela definiçâo e pela implementação das diretrizes de mudança no setor saúde, foi a organização básica para o presente estudo.

Considerando as características do processo de gerenciamento dos serviços públicos de saúde na década de 80, o presente estudo teve como eixo principal a análise do papel da Comissão Interinstitucional de Saúde (CIS), que se constituiu na instância colegiada de maior poder na estrutura de transição da Secretaria da Saúde e do qual emanava diretrizes para todas as outras instâncias de gestāo colegiada no Estado.

A lenta expansão das AIS, observada no inicio da década, corroborado pelo fato de que a reestruturação da Secretaria da Saúde ocorrida em 1985 deu forte impulso ao processo de descentralização e de estímulo à gestão colegiada, a coleta de informaçōes foi direcionada ao periodo de 1985-89.

A recuperaçāo das atas de reuniōes da CIS$\mathrm{SP}$, bem como das resoluçōes e decretos, visou identificar as modificações ocorridas nas atribuições e nas competências dessa instância, suas repercussões e possíveis reflexos na prestação final dos serviços de saúde.

Objetivando complementar a coleta de da- dos sobre o processo institucional de gerenciamento do setor saúde, foram consultados documentos na Fundação para o Desenvolvimento Administrativo do Estado de São Paulo (FUNDAP) e na Faculdade de Saúde Pública (FSP/USP).

Todas as atas das reuniōes da CIS-SP coletadas foram analisadas e de seu conteúdo foram extraídos os seguintes dados: participação dos representantes nas reuniōes de diferentes níveis de governo: federal, estadual e municipal e da comunidade, os assuntos mais discutidos, e aqueles agendados com maior freqüência para serem discutidos; tipo e quantidade de reuniões e tipo de decisão tomada pelo colegiado.

Com a intenção de verificar nas agendas das reuniōes da CIS-SP o caráter mais freqüente dos assuntos, nelas tratados, optou-se por classificá-los como: administrativos, decisórios e burocráticos. Assim, considerou-se como:

- assuntos administrativos, aqueles referentes à implantação do SUDS-SP, a aprovação de financiamentos, análise de repasses e demais temas semelhantes;

- assuntos burocráticos, os referentes a resoluções a serem referendadas pelo colegiado, documentos para aprovação, e retificação de convênios; $\mathrm{e}$

- assuntos decisórios, aqueles que geravam providências imediatas através do estabelecimento de atos normativos.

Visando a melhor identificaçāo do tipo de decisão adotada pelo colegiado nas reuniōes, foram recuperadas informações através das atas que permitiram a seguinte categorização: decisões "ad referendum" da Comissão e decisōes por consenso do colegiado.

Através das resoluções CIS-SP coletadas foi possível identificar o tipo, a abrangência e a magnitude das decisões tomadas pelo colegiado.

A coleta de documentos relativos ao processo de gerenciamento do setor saúde no Estado de São Paulo, realizada junto a SES-SP, FUNDAP e Faculdade de Saúde Pública/USP propiciou que fossem estudados e analisados, pela equipe, cerca de 462 documentos, dos quais 27 eram decretos estaduais, 17 resoluçōes federais e 258 resoluções estaduais, publicados no período de 1980 a 1989.

A partir da pesquisa documental foi possivel identificar alguns marcos referenciais na década de 80 na função de gerenciamento do setor saúde no Estado, sendo estes: até o ano de 1983, por ocasião da assinatura do Termo Aditivo e do Termo de Adesão às AIS, em nível federal, estadual e no Município de São Paulo, quando se 
iniciou uma nova forma de gestão dos serviços de saúde; o ano de 1985, quando ocorreu a reestruturação da SES-SP; e o ano de $1987 \mathrm{com}$ a criação do Programa Sistema Unificado e Descentralizado de Saúde (SUDS), no Estado de São Paulo. Estas "datas-marco" foram utilizadas para análise dos dados coletados.

\section{Resultados e Análise}

A proposta de gestão colegiada foi a estratégia fundamental das AIS, e desta forma entender o processo de funcionamento da CIS-SP é fundamental para o acompanhamento das diferentes etapas do processo. Para tanto, vale a pena recuperar o documento básica das AIS, que foi publicado em 19849 , que estabelece as seguintes diretrizes e orientaçōes getais: - "a responsabilidade do Estado pela saúde dos indivíduos; a integração interinstitucional; a elaboração de programas, a partir de um diagnóstico de saúde; a busca da integralidade, regionalização e hierarquização do setor público e privado; a coparticipação claramente definida das várias instituições envolvidas no financiamento das açōes de sáude, de acordo com as responsabilidades institucionais; e o reconhecimento da legitimidade de participação dos vários segmentos sociais na definição das necessidades, no encaminhamento de soluçōes e na avaliação do nível de desempenho da assistência prestada".

Partindo dos marcos referenciais e dos dados coletados na CIS-SP foi possível identificar que, no início do colegiado (1985) existiam certas dificuldades na tomada de decisões por parte dos representantes dos diferentes níveis do poder público, em virtude da administração centralizada dos órgãos federais.

A maior parte das discussōes referiram-se, até 1988, à co-gestão com o INAMPS de seus equipamentos constituindo-se $48,30 \%$ dos assuntos discutidos em 1985, 27,80\% em 1986, $39,60 \%$ em 1987 e $23,50 \%$ em 1988.

O INAMPS, por meio de seus representantes, trazia ao colegiado decisōes conflitivas que, muitas vezes, poderiam implicar em enfrentamento com os setores articulados de prestação de serviços ou mesmo decisões dificies de serem assumidas isoladamente pelo próprio órgão, dada a sua correlação de forças. A Superintendência Regional do INAMPS, trazia para a CIS-SP problemas pontuais de difícil resolução. Os repasses financeiros para os Termos Aditivos aos outros níveis do poder público, no início das AIS, não possuiam limites estabelecidos, mas em 1985 já existiam "tetos" globais para o Es- tado, que deveriam ser compatibilizados nas instâncias gestoras.

Além da co-gestão com o INAMPS, os assuntos que durante todos os momentos estudados permearam as reuniōes da CIS-SP foram os seguintes: a implantação das AIS e posteriormente do SUDS-SP, a adesão aos respectivos convênios, o planejamento em saúde, as discussões sobre programas de saúde, a municipalização, os recursos humanos e a formação de grupos técnicos e comissōes de assessoria*.

Até 1985, a CIS-SP ainda demonstrava certa dificuldade na tomada de decisão, principalmente porque a sua Secretaria Executiva permanecia apenas como instância "burocrática" de encaminhamento, não realizando o trabalho técnico preparatório dos assuntos para tomada de decisão nas reuniōes, devido à indefinição de papel. A tomada de decisōes, muitas vezes, foi desempenhada de maneira isolada pelos representantes de cada instituição, o que gerou alguns conflitos. Apesar dessas dificuldades, os técnicos da Secretaria Executiva, nos anos de 1984 e 1985 viabilizaram a implantação dos Planos de Aplicação da AIS, através das Diretorias Regionais da Secretaria de Saúde ${ }^{\star * 12}$.

A reestruturação da SES-SP, a partir da reforma administrativa de 1985 implantada pelo Governo do Estado, veio aliar-se à política de descentralização e regionalização do setor saúde proposta pelas AIS, propiciando um fortalecimento da gestão colegiada, através da criação de 62 Escritórios Regionais de Saúde (ERSA).

$\mathrm{Na}$ estrutura antiga da SES-SP, a tramitação do convênio AIS era difícil, pois implicava sua apreciação por apenas 12 CRIS. Na nova estrutura a apreciação do convênio passou a ser realizada por 62 CRIS constituídas a partir dos ERSA, propiciando a racionalização do processo de decisão e maior integração entre o Estado e os municípios ${ }^{18}$.

A paulatina expansāo das AIS e a conseqüente implantação das CRIS e CIMS, propiciou certa diluição do poder decisório da CIS-SP, que a partir deste momento, passou a assumir o papel de instância de consolidação dos Planos $\mathrm{Mu}$ nicipais de Aplicação.

No período de 1983 a 1985, apesar da implantaçäo dos órgãos colegiados no Estado de São Paulo, principalmente da CIS-SP, ficou claro que as decisões tomadas por esta instância deliberativa eram ainda, predominantemente, aquelas de interesse do INAMPS.

* Atas das Reunióes da CIS-SP, 1985-1989.

* Ofício circular $n^{2}$ 0001/87 do Departamento Técnico Normativo da Secretaria do Estado da Saúde de São Paulo. 
$\mathrm{Na}$ composição da CIS-SP, inicialmente, além da participação da SES-SP, através do seu Secretário, e do INAMPS, através do seu Superintendente Regional, estavam previstas a participação do Ministério da Saúde e o da Educação, através de seus respectivos representantes. Ao analisar-se as atas das reuniōes do colegiado, em 1985, observou-se que $35,70 \%$ de seus representantes eram do nivel federal, $34,30 \%$ do nível estadual (central e intermediário da SESSP), $11,40 \%$ do Município de São Paulo* e $18,60 \%$ da comunidade ${ }^{* *}$. A pequena percentagem de representantes da comunidade nas reuniões era constituída, em realidade, predominantemente, por técnicos do setor saúde, sem direito a voto (Tabela 1). Em 1986, houve aumento na participação do nível federal, em virtude da inclusão do representante do Ministério da Educação (ME), prevista desde a criação da CIS. Verificou-se, também, aumento de representantes do nivel intermediário da SES-SP (Tabela 2).

Tabela 1 - Número e percentagem de reunióes da Comissåo Interinstitucional de Saúde (CIS), segundo tipo, no Estado de São Paulo, no período de 1985 a 1989.

\begin{tabular}{|c|c|c|c|c|c|c|}
\hline \multirow[b]{3}{*}{ Ano } & \multicolumn{4}{|c|}{ Reuniōes (Tipo) } & \multirow{2}{*}{\multicolumn{2}{|c|}{ Total }} \\
\hline & \multicolumn{2}{|c|}{ Ordinárias } & \multicolumn{2}{|c|}{ Extraordinárias } & & \\
\hline & $N^{2}$ & $\%$ & № & $\%$ & $N^{2}$ & $\%$ \\
\hline 1985 & 2 & 8 & 8 & 47,1 & 10 & 23,8 \\
\hline 1986 & 9 & 36 & 3 & 17,6 & 12 & 28,5 \\
\hline 1987 & 3 & 12 & 3 & 17,6 & 6 & 14,2 \\
\hline 1988 & 5 & 20 & 2 & 11,8 & 7 & 16,7 \\
\hline 1989 & 6 & 24 & 1 & 5,9 & 7 & 16,7 \\
\hline Total & 25 & 100 & 17 & 100 & 42 & 100 \\
\hline
\end{tabular}

Em 1987, apesar da dificuldade sentida por alguns técnicos da SES-SP devido à reforma administrativa, em relação principalmente, à coleta de informaçōes, a SES-SP apresentava uma estrutura mais horizontalizada, facilitando a implantação do novo modelo de assistência proposto pelas AIS e particularmente pelo SUDS.

A mudança do governo estadual em 1987, aliada à implantação do SUDS-SP, fez com que ocorresse um esvaziamento dos órgãos colegiados das AIS, enquanto instâncias de decisão e

\footnotetext{
* Embora a participação do representante do Município de São Paulo não ter sido prevista na composiçāo da CIS-SP até este momento, a sua participação "ad loc" ocorreu, tendo em vista as prioridades do município e a afinidade do Secretário Municipal com o poder estadual e a importância do município no contexto político institucional das AIS.

* Atas das reuniōes da CIS-SP, 1985-1989.
}

de planejamento de saúde.

Por uma situação peculiar, o novo Secretário de Estado da Saúde passou a acumular as funçōes do Superintendente do INAMPS, sendo assim possivel a alocação dos recursos orçamentários das duas instituiçōes ao nível do Fundo Estadual de Saúde (FUNDES). Concomitantemente, foi desenvolvida uma estratégia de integrar funcional e fisicamente a Superintendência Regional do INAMPS à estrutura da SES-SP.

A composição da CIS, a partir de então, sofreu algumas modificações. O Estado de São Paulo passou a ser representado, predominantemente, por participantes do nível central da SESSP. O Município de Sāo Paulo, durante este ano, não foi mais representado nas reuniões do colegiado.

Em junho de 1987, a Resoluçāo CIS-SP 32/87 agregou formalmente à estrutura do colegiado a Secretaria Executiva e alguns grupos de trabalho. Também, oficializou a representação dos Sectetários Municipais de Saúde, que no entanto, passaram a estar presentes, efetivamente, nas reuniōes apenas no ano seguinte ${ }^{14}$ (Tabela 2).

No mês de setembro de 1987 , foram constituídas as Câmaras Consultivas na SES-SP. Estas eram constituidas por representantes de vários segmentos da sociedade civil, especialmente dos usuários do sistema de saúde, dos recursos humanos do setor, das organizaçōes prestadoras de serviços de saúde e dos órgãos governamentais relacionados com o SUDS-SP; porém, a participação das Câmaras Consultivas nas reuniões da CIS-SP sempre foi mínima ${ }^{15}$ (Tabela 2).

$O$ acúmulo de funções na pessoa do Secretário fez com que a Secretaria de Saúde se tornasse, simultaneamente, prestador e ordenador dos serviços públicos de assistência médica, no âmbito da Previdência Social.

De 1987 em diante é possivel notar tendência, cada vez maio, de consolidar-se o papel da Secretária de Estado da Saúde enquanto gestor principal do setor no Estado. Em maior de 1988, um decreto do governador do Estado reconhecia - SUDS como estrutura organizada de ações de saúde, sob a condução da Secretária de Estado da Saúde. Em um dos artigos do documento era salientado que o Secretário de Estado da Saúde deveria propor ao governador do Estado, a adequaçāo das estruturas e normas operacionais da SES-SP, as responsabilidades do Estado no SUDS ouvindo, quando fosse o caso, a CIS-SP ${ }^{6}$.

Portanto, a junção funcional ocorrida na direção das instituições públicas de nível estadual, prestadoras de serviços de saúde, resultou, na 
Tabela 2 - Número e percentagem de representantes, junto à Comissão Interinstitucional de Saúde (CIS) segundo niveis de governo e instituiçōes no Estado de Sâo Paulo, de 1985 a 1989.

\begin{tabular}{|c|c|c|c|c|c|c|c|c|c|c|c|c|c|}
\hline \multirow{3}{*}{ Instituiçס̄es } & & \multicolumn{12}{|c|}{ Ano } \\
\hline & & \multicolumn{2}{|c|}{1985} & \multicolumn{2}{|c|}{1986} & \multicolumn{2}{|c|}{1987} & \multicolumn{2}{|c|}{1988} & \multicolumn{2}{|c|}{1989} & \multicolumn{2}{|c|}{ Total } \\
\hline & & $\mathrm{N}^{2}$ & $\%$ & $\mathbf{N}^{2}$ & $\%$ & $\mathrm{~N}^{2}$ & $\%$ & $N^{2}$ & $\%$ & $N^{2}$ & $\%$ & $N^{2}$ & $\%$ \\
\hline \multirow[t]{5}{*}{ Federal } & Min. Saúde & 9 & 36,0 & 14 & 25,9 & 9 & 33,3 & 12 & 37,5 & 10 & 25,6 & 54 & 30,5 \\
\hline & $\begin{array}{l}\text { Min. Prev. } \\
\text { Assist. Social }\end{array}$ & 16 & 64,0 & 35 & 64,8 & 13 & 48,1 & 4 & 12,5 & 8 & 20,5 & 76 & 42,9 \\
\hline & Min. Educação & & & 5 & 9,3 & 5 & 18,6 & 12 & 37,5 & 12 & 30,8 & 34 & 19,2 \\
\hline & Min. Trabalho & & & & & & & 4 & 12,5 & 9 & 23,1 & 13 & 7,3 \\
\hline & Sub-Total & 25 & 35,7 & 54 & 40,6 & 27 & 38,0 & 32 & 37,2 & 39 & 34,5 & 177 & 37,4 \\
\hline \multirow[t]{3}{*}{ Estadual } & SES-Central & 18 & 75,0 & 60 & 81,1 & 23 & 100 & 35 & 79,5 & 45 & 91,8 & 181 & 84,6 \\
\hline & SES-Inter. & 6 & 25,0 & 14 & 18,9 & & & 9 & 20,5 & 4 & 8,2 & 33 & 15,4 \\
\hline & Sub-Total & 24 & 34,3 & 74 & 55,6 & 23 & 32,4 & 44 & 51,2 & 49 & 43,4 & 214 & 45,2 \\
\hline \multirow[t]{3}{*}{ Municipal } & SHS-SP & 8 & 100 & 1 & 100 & & & 1 & 10,0 & 7 & 29,2 & 17 & 39,5 \\
\hline & SHS-Interior & & & & & & & 9 & 90,0 & 17 & 70,8 & 26 & 60,5 \\
\hline & Sub-Total & 8 & 11,4 & 1 & 0,8 & & & 10 & 11,6 & 24 & 21,2 & 43 & 9,1 \\
\hline Participação & Ass. Classe & & & 2 & 50,0 & 3 & 14,3 & $\cdot$ & & & & 5 & 12,8 \\
\hline \multirow[t]{3}{*}{ Comunitária } & Sociedade Civil & & & & & & & & & 1 & 100 & 1 & 2,6 \\
\hline & Outros s/ voto & 13 & 100,0 & 2 & 50,0 & 18 & 85,7 & & & & & 33 & 84,6 \\
\hline & Sub-Total & 13 & 18,6 & 4 & 3,0 & 21 & 29,6 & & & 1 & 0,9 & 39 & 8,2 \\
\hline Total & & 70 & 100 & 133 & 100 & 71 & 100 & 86 & 100 & 113 & 100 & 473 & 100 \\
\hline
\end{tabular}

Fontes: Atas/CIS.SP

SES - Secretaria de Estado da Saúde

SHS - Secretaria de Higiene e Saúde

prática, em uma forma de gestão única, não havendo necessidade de "negociar" em uma instância colegiada temas controversos ou contrários aos interesses da Secretaria da Saúde.

A tendência da centralização da CIS-SP na pessoa do Secretário de Saúde foi possivel de ser identificada na investigação sobre a maneira com que as 111 resoluçōes CIS-SP foram aprovadas em 1988; 68,50\% destas constituiram-se aprovaçōes "ad referendum" do colegiado, $20,70 \%$ foram deliberadas nas reuniōes do colegiado, e $10,80 \%$ não foi possível obter-se informações sobre a maneira com que foram aprovadas nas atas.

É interessante confrontar o número de Resoluçōes CIS-SP com a quantidade de reuniōes do colegiado; por exemplo em 1988, ocorreram apenas 7 reuniões da CIS-SP (5 ordinárias e 2 extraordinárias) tendo sido publicadas 111 resoluçōes (Tabela 1).

É possível notar, ainda, que os assuntos discutidos na CIS-SP em 1988, passaram a ter um caráter mais "burocrático" (Tabela 3); e que com o avanço do processo de implantação do SUDSSP ocorreu um declínio no assunto AIS, nas discussōes, como era de se prever.

A maioria das Resoluções CIS-SP publicadas e levadas "a posteriori" para serem referendadas pelo colegiado eram relativas à implantação e adesão ao SUDS-SP (Tabela 4).

A partir de 1988 passaram a ser incluídos nas reuniões da CIS-SP, representantes do $\mathrm{Mi}$ -

Tabela 3 - Número e caráter dos assuntos presentes nas reuniōes da Comissão Interinstitucional de Saúde (CIS), Estado de São Paulo, 1985 a 1989.

\begin{tabular}{|c|c|c|c|c|c|c|c|c|c|c|c|c|}
\hline \multirow{3}{*}{$\begin{array}{l}\text { Tipo de } \\
\text { Assunto }\end{array}$} & \multicolumn{10}{|c|}{ Ano } & & \\
\hline & \multicolumn{2}{|c|}{1985} & \multicolumn{2}{|c|}{1986} & \multicolumn{2}{|c|}{1987} & \multicolumn{2}{|c|}{1988} & \multicolumn{2}{|c|}{1989} & \multicolumn{2}{|c|}{ Total } \\
\hline & Ne & $\%$ & $N^{2}$ & $\%$ & № & $\%$ & Ne & $\%$ & $N^{2}$ & $\%$ & $\mathrm{~N}^{2}$ & $\%$ \\
\hline Administrativo & 17 & 31,5 & 17 & 28,8 & 23 & 32,9 & 13 & 23,2 & 25 & 51,0 & 95 & 31,9 \\
\hline Burocrático & 4 & 7,4 & 8 & 13,6 & 5 & 7,1 & 17 & 30,4 & 1 & 2,0 & 45 & 15,1 \\
\hline Decisório & 25 & 46,3 & 29 & 49,1 & 32 & 45,7 & 25 & 44,6 & 13 & 26,5 & 124 & 41,6 \\
\hline Comunicados & 8 & 14,8 & 5 & 8,5 & 10 & 14,3 & 1 & 1,8 & 10 & 20,4 & 34 & 11,4 \\
\hline Total & 54 & 100 & 59 & 100 & 70 & 100 & 56 & 100 & 49 & 100 & 298 & 100 \\
\hline
\end{tabular}

Fonte: Atas das reuniōes CIS.SP, 1985 a 1989 
Tabela 4 - Número e percentagem de resoluçỏes da Comissăo Interinstitucional de Saúde (CIS), Estado de Săo Paulo, no periodo de 1987 a 1989.

\begin{tabular}{|c|c|c|c|c|c|c|c|c|}
\hline \multirow[b]{3}{*}{ Assunto } & \multicolumn{6}{|c|}{ Ano } & & \\
\hline & \multicolumn{2}{|c|}{1987} & \multicolumn{2}{|c|}{1988} & \multicolumn{2}{|c|}{1989} & \multicolumn{2}{|c|}{ Total } \\
\hline & $\mathbf{N}^{2}$ & $\%$ & $\mathbf{N}^{2}$ & $\%$ & $\mathrm{~N}^{2}$ & $\%$ & $\mathrm{~N}^{2}$ & $\%$ \\
\hline AIS & 8 & 14,0 & 5 & 4,5 & & & 13 & 5,0 \\
\hline Programa/Diretor & 2 & 3,5 & 1 & 0,9 & 1 & 1,1 & 4 & 1,6 \\
\hline $\begin{array}{l}\text { Exec. Orçamento } \\
\text { Financiamento }\end{array}$ & 6 & 10,5 & 8 & 7,2 & 2 & 2,2 & 16 & 6,2 \\
\hline $\begin{array}{l}\text { Grupo Trab. e } \\
\text { Comissóes }\end{array}$ & 21 & 36,9 & 3 & 2,7 & 2 & 2,2 & 26 & 10,1 \\
\hline SUDS (SP) - Geral & 13 & 22,8 & 32 & 28,8 & 35 & 39 & 80 & 31,0 \\
\hline Adesão aos SUDS & 2 & 3,5 & 38 & 34,3 & 30 & 33,3 & 70 & 27,1 \\
\hline Recursos Humanos & 2 & 3,5 & 8 & 7,2 & 11 & 12,2 & 21 & 8,1 \\
\hline $\begin{array}{l}\text { Creden./Contratos/ } \\
\text { Convénios }\end{array}$ & 1 & 1,8 & 6 & 5,4 & 8 & 8,9 & 15 & 5,9 \\
\hline Outros & 2 & 3,5 & 10 & 9,0 & 1 & 1,1 & 13 & 5,0 \\
\hline Total & 57 & 100 & 111 & 100 & 90 & 100 & 258 & 100 \\
\hline
\end{tabular}

Fonte: Ementário de Atos Deliberativoss - Normativos CIS/SP de 1987 a 1990.

AIS - Ações Integradas de Saúde

SUDS - Sistema Unificado e Descentralizado de Saúde.

nistério do Trabalho (MT), que embora estivessem com sua participação prevista desde a criação do colegiado, esta ainda não havia se efetivado (Tabela 2).

Apesar da tendência centralizadora verificada no CIS-SP neste período, em agosto de 1988, uma das Resoluçōes CIS-SP instituiu na SUDSSP o Sistema Interinstitucional de Deliberação Colegiada, recriando dentro do novo sistema as mesmas estruturas de gestão colegiada das AIS15.

Segundo a mesma Resoluçäo CIS-SP citada acima, até 1989 a CIS-SP deveria ser composta por 4 representantes da SES-SP, sendo um deles, o seu Presidente, o Secretário do Estado da Saúde; 2 representantes de cada Ministério, sendo um deles o Chefe do Escritório Regional do INAMPS, 3 representantes da organização dos Secretários de Saúde do Estado de São Paulo, 2 representantes dos usuários do sistema, sendo um deles escolhido pelos representantes das organizações trabalhadoras e outro, pelos representantes das organizações patronais, escolhido entre seus pares nas Câmaras Consultivas correspondentes.

Numa análise comparativa com a composição real do colegiado, obtida através das atas das reuniōes da CIS-SP em 1989, verificou-se que a sua composição em nível federal manteve-se com 5,57 representantes em média, por reuniāo. $\mathrm{O}$ nível estadual participou com maior peso do que nos anteriores, com uma média de 7 representantes por reunião e o nível municipal manteve-se aproximadamente dentro do previsto com uma média de 3,42 representantes por reuniảo (Tabelas 1 e 2).

O processo de municipalização veio proporcionar ao município a gestão da rede básica de saúde. Ao nível regional da SES-SP coube o relacionamento com a Previdência e com os serviços hospitalares e de especialidade do setor público. A separação das responsabilidades e funções entre estes níveis, concomitante ao enfraquecimento do INAMPS na prestação direta de serviços, praticamente aniquilou o processo de gestão colegiada, iniciado pelas AIS. Essa mudança de papéis fez com que, paulatinamente, o gerenciamento fosse se tornando único a cada nível do governo.

O Estado, ao absorver as funções do INAMPS, passou a ser o responsável pela interface com o setor privado, assumindo maior definição de papel e maior poder comparativamente ao início da década, na vigência das AIS.

\section{Consideraçōes Finais}

O gerenciamento dos equipamentos públicos de saúde, no início da década de 80 , era realizado de maneira isolado, pelos diferentes níveis de governo, com funções claramente definidas.

O nivel federal, através do Ministério da Previdência e Assistência Social (MPAS), tendo como instituiçāo executora, o INAMPS, responsabilizava-se por oferecer assistência médica in- 
dividual de caráter curativo, principalmente dirigida à população formalmente inserida no processo de trabalho, através de equipamentos próprios, ou equipamentos privados conveniados e contratados.

O gerenciamento tinha como característica principal a questão da tecnologia médica predominantemente voltada à assistência hospitalar.

As formas de gerenciamento colegiado, integrado ou articulado existiam sem apoio legal, dependendo basicamente do interesse de indivíduos, que ocupando cargos de direção, procuravam compartilhar o processo de decisão ou integrá-lo numa proposta mais ampla de reorganização do setor saúde. Com o advento das AIS e a criação das Comissões Interinstitucionais de Saúde a nível de estado, regiảo e município houve um impulso na gestão colegiada.

No entanto, apesar dos princípios e das propostas previstas para funcionamento da Comissão Interinstitucional de Saúde do Estado de São Paulo, verificou-se que a grande maioria dos assuntos nela tratados referiam-se basicamente à relação do INAMPS com o setor público de saúde estadual ou municipal. A postura por parte dos representantes do INAMPS na CIS-SP era a de compradores em relação a vendedores de serviços públicos do Estado ou do município. $O$ Estado e os municípios levavam ao colegiado os assuntos relativos à sua adaptação ao INAMPS, e a questões que, na maioria das vezes, decorriam das decisões centralizadas do mesmo.

As comissões interinstitucionais, que deveriam ser locais de tomada de decisões, foram caracterizando-se como instâncias de disputa de poder, onde os próprios argumentos técnicos financeiros eram analisados por óticas distintas, sem que houvesse a construção de uma decisão colegiada.

A partir da criação do SUDS, por decreto, as comissões interinstitucionais começam a perdet força. As AIS pressupunham e exigiam decisōes colegiadas para o seu processo de implementação, expansão e controle, entretanto, o SUDS, ao estabelecer a estadualização e a municipalização e ao definir a passagem das responsabilidades da prestação de serviços de saúde, dos serviços próprios e do setor privado, para o Estado, definia claramente novos papéis. O SUDS conferindo ao município a responsabilidade de operar na rede básica, veio transformar, substancialmente, a forma e o aspecto político das comissões.

Com a estadualização e e municipalização da saúde, as comissōes deixam de ser "arenas" de disputa do poder e as responsabilidades e os poderes das diferentes niveis tornam-se mais claramente definidos.

Desta maneira, a SES-SP passa a ser o órgāo pagador do setor público e do setor privado e o INAMPS a exercer o controle no sistema sem responsabilidade de sua operacionalização.

Essa mudança foi rapidamente compreendida pelo Sectetário de Saúde que assumiu o comando do Sistema no Estado de São Paulo. A CIS-SP perdeu parte das suas funções anteriores e a estrutura do INAMPS foi acoplada à da SES-SP.

O município passou a ter outro tipo de relação com o Estado que passou de intermediário à financiador do setor público municipal.

Assim, o gerenciamento dos serviços de saúde no Estado de São Paulo, que no começo da década de 80 propunha-se a ser colegiado, ao seu final tornou-se único e bem diferenciado, sob responsabilidade direta do Estado e dos municípios.

O INAMPS ao delegar, praticamente, todo o gerenciamento do setor, ficou com a função de fonte financiadora de maneira semelhante a um "banco" que arrecada e distribui recursos mediante suas políticas maiores, delegando o controle e a operacionalização da rede privada ao nível estadual e municipal.

TANAKA, O.Y. et al.[Health management in the State of S. Paulo, Brazill]. Rev. Saúde públ., S. Paulo, 26: 185-94, 1992. The shared management put into effect by the "Açōes Integradas de Saúde" (Integrated Health Actions) in the State of S. Paulo (Brazil), in the early 80 s is analysed. The relevant data were collected from the minutes of the meetings of the "Comissão Interinstitutional de Saude" (Interinstitucional Health Commitee). The data collected show the most frequent subjects discussed by the members at the meetings, the number of members related to each of the different government levels, in addition to the kind of resolutions taken at the meetings. The data analysis has demonstrated that important changes took place in public health management in the State of $S$. Paulo in the decade in question. The shared management process was replaced by one in which government powers were clearly divided a towards the end of the 80 s. Those changes have led the public health members from each level of governmental administration to give up the common goals and the shared negociations among them.

Keywords: Public administraction, trends. Interinstitutional relations. Public health administraction, trends. Health system, organization and administraction. 


\section{Referências Bibliográficas}

1. CONFERENCIA INTERNACIONAL SOBRE CUIDADOS PRIMÁRIOS À SAUUDE. Alma-Ata, URSS, 1978. Relatório final. Brasilia, OMS/UNICEF, 1979.

2. CONFERENCIA NACIONAL DE SAÚDE, 5^, Brasília, 1975. Anais. Brasília, Ministério da Saúde, 1975.

3. CONFERENCIA NACIONAL DE SAÚDE, 64 , Brasília, 1977. Anais. Brasillia, Ministério da Saúde, 1977.

4. CONFERENCIA NACIONAL DE SAÚDE, 7\%, Brasília, 1980. Anais. Brasília, Ministério da Saúde, 1980.

5. COMISSÃO INTERMINISTERIAL DE PLANEJAMENTO (CIPLAN). Resolução $n^{2}$ 6, de 3 de maio de 1984: aprova as Ações Integradas de Saúde (AIS) e o documento Normas Gerais Aplicáveis às AIS. In: Ementário de atos da CIPLAN: 1980-1988. Brasília, 1989.

6. DECRETO $n^{2} 28.410$, de 25 de maio de 1988: dispõe sobre o Sistema Unificado e Descentralizado de Saude do Estado de São Paulo (SUDS-SP). São Paulo, Secretaria de Estado do Governo, 1988.

7. INSTITUTO NACIONAL DE ASSISTENCIA MÉDICA DA PREVIDENCIA SOCLAL (INAMPS). São Paulo: Sistema Unificado e Descentralizado de Saúde. Brasilia, 1987.

8. MINISTÉIO DA PREVIDENCIA E ASSISTENCIA SOCIAL. Reorientação da assisténcia à saúde no ámbito da Previdéncia Social. Brasilia, 1983.

9. MINISTÉRIO DA PREVIDENCIA E ASSISTENCIA SOCIAL / MINISTÉRIO DA SAÚDE / MINISTERIO DA EDUCAÇAOO / GOVERNOS ESTADUAIS E MUNICIPAIS. Açōes Integradas de Saude. Brasilia, 1984.

10. MINISTERIO DA SAUUDE / MINISTERIO DA PREVIDENCIA E ASSISTENCIA SOCIAL / SECRETARIA DO PLANEJAMENTO DA PRESIDENCIA DA REPÚBLICA. Programa Nacional de Serviços Básicos de Saúde (PREV-SAÚDE). Brasilia, 1980. [Doc. versão preliminar].
11. PRESIDENCLA DA REPÚBLICA. Exposição de motivos $n^{2} 31$, de 10 de julho de 1987: estabelece as diretrizes para que através do SUDS se consolidem as AIS. Diário Oficial da União, 21 jul. 1987.

12. SECRETARIA DE ESTADO DA SAÚDE DE SÃO PAULO. Balanço geral do primeiro ano das AIS. São Paulo, 1984.

13. SECRETARIA DE ESTADO DA SAÚDE DE SÅO PAULO. Primeiro termo aditivo ao convênio $7 / 83$. Diário Oficial do Estado de São Paulo, 9 nov. 1983.

14. SECRETARIA DE ESTADO DA SAÚDE DE SÃO PAULO. Resolução CIS-SP $\Omega^{2} 32 / 87$, de 11 de fevereiro de 1987: define o regimento intemo da CIS-SP. In: Ementário de atos deliberativos normativos da CIS-SP: 1987-1990. São Paulo, 1990.

15. SECRETARIA DE ESTADO DA SAÚDE DE SÃO PAULO. Resolução CIS-SP n 59/87, de 3 de setembro de 1987: institui as Câmaras Consultivas no SUDS-SP. In: Ementário de atos deliberativosnormativos da CIS-SP: 1987-1990. São Paulo, 1990.

16. SECRETARIA DE ESTADO DA SAÚDE DE SÃO PAULO. Resolução CIS-SP $n^{2} 56 / 88$, de 24 de agosto de 1988: institui no SUDS-SP o Sistema Interinstitucional de Deliberação Colegiada. São Paulo, Gabinete do Secretário, 1988.

17. TANAKA, O.Y. Análise da utilização dos serviços de postos de assistência médica e do atendimento do Jardim São Jorge, no Município de São Paulo, por meio do estudo da clientela usuária. Sảo Paulo, 1988. [Tese de Doutoramento - Faculdade de Saúde Pública da USP].

18. TANAKA, O.Y. et al. Estudo comparativo das açōes integradas de saúde AIS no Estado de São Paulo: análise do processo interinstitucional de planejamento e gerenciamento. São Paulo, 1991.

Recebido para publicação em 22/10/1991 Reapresentado em 21/2/1992 Aprovado para publicação em 28/2/1992 